\title{
ATIVIDADE MOLUSCICIDA DA MISTURA DE ÁCIDOS 6-n-ALQUIL SALICÍLICOS (ÁCIDO ANACÁRDICO) E DOS SEUS COMPLEXOS COM COBRE (II) E CHUMBO (II)
}

\author{
Nelymar Martineli Mendes, Alaide Braga de Oliveira, \\ João Edmundo Guimarães, José Pedro Pereira e Naftale Katz
}

\begin{abstract}
Foi comparada, em laboratório, a atividade moluscicida do extrato hexânico da casca da castanha do caju - Anacardium occidentale $L$. (EHCCC), do complexo de cobre (II), do complexo de chumbo (II) e do ácido anacárdico com objetivo de encontrar entre eles um produto que apresentasse maior estabilidade que o ácido anacárdico. Este foi preparado tratando o EHCCC com hidróxido de chumbo(II) ou com o sulfato de cobre mais hidróxido de sódio ou com hidróxido de cobre (II). Em seguida, o complexo de chumbo (II) ou os complexos de cobre (II) preparados foram tratados com uma solução de ácido sulfúrico diluída. As misturas dos dez produtos obtidos foram testadas sobre caramujos adultos de Biomphalaria glabrata nas concentraçōes de 1 a 10 ppm. Os mais ativos foram o complexo de cobre (II), obtido com sulfato de cobre mais hidróxido de sódio, e o ácido anacárdico (hidróxido de chumbo) que apresentaram atividade a partir da concentrafão de 4 ppm. O teor de chumbo do ácido anacárdico (hidróxido de chumbo) foi acima das normas recomendadas pelos Padrões de Saúde Pública dos Estados Unidos.
\end{abstract}

Palavras-chaves: Biomphalaria glabrata. Acido anacárdico. Complexo. Moluscicida.

\section{O Anacardium occidentale L., Anacardiaceae} (caju) é uma planta nativa dos campos e dunas da costa do nordeste brasileiro, sendo hoje encontrada na América Tropical, nas Antilhas e em várias regiões da África, Ceilão e Índia ${ }^{2}$.

O óleo extraído da casca da castanha de caju contém ácido gálico, sais minerais, substâncias nitrogenadas e sulfuradas, sacarideos e fenóis. Estes são formados por quatro tipos de misturas n-alquil fenólicas constituídas por derivados de ácido salicílico (ácido anacárdico), derivados de resorcinol (cardol e 2-metil cardol) e monofenóis (cardanol). Os termos ácido anacárdico, cardol, 2-metil cardol e cardanol são usados para descrever respectivamente, as misturas de ácidos 6-n-alquil salićlicos, 5-n-alquil resorcinois, 2metil 5-n-alquil resorcinois e 3-n-alquil fenóis 18 (Figura 1).

Tyman, em 1973, descreveu as estruturas quimicas dos quatro constituintes da mistura de ácidos 6n-alquil salicílicos ${ }^{16}$. A cadeia lateral com quinze átomos de carbono se encontra em posição meta em relação ao grupo hidroxila $(\mathrm{OH})$ e nessa cadeia o valor de $n$ pode variar de $0,2,4,6$ (Figura 1). Na cadeia saturada (C15 H31); $n$ é igual a zero e nas cadeias

Centro de Pesquisas "René Rachou"/Fundação Oswaldo Cruz, Belo Horizonte, MG, Brasil.

Departamento de Química do Instituto de Ciências Exatas, Universidade Federal de Minas Gerais, Belo Horizonte, MG, Brasil.

Suporte financeiro fornecido pela Financiadora de Estudos e Projetos (FINEP), convênio no 42890023.00.

Endereço para correspondência: Dra. Nelymar Martineli Mendes, Av. Augusto de Lima 1715, Barro Preto, 30190 Belo Horizonte, MG, Brasil.

Recebido para publicação em 08/05/90. insaturadas (C15 H29), (C15 H27) e (C15 H25) $n$ é igual a dois, quatro e seis, respectivamente (Figura 2).

A atividade moluscicida sobre Biomphalaria glabrata da casca da castanha do caju foi demonstrada pela primeira vez, em laboratório e no campo, por Pereira e Souza 12 .

Posteriormente, Sullivan e cols evidenciaram que o componente trieno do ácido anacárdico apresentou para B. glabrata as concentrações letais (CL50 e CL90) em doses mais baixas que o dieno, o monoeno, o ácido anacárdico de cadeia saturada e o cardanal 15

O ácido anacárdico é prontamente descarboxilado em cardanol quando submetido a um tratamento térmico ${ }^{6}$ ou pode sofrer polimerização quando armazenado à temperatura ambiente por um ano ou mais 10 .

No presente trabalho, objetivando obter complexo do ácido anacárdico que apresentasse maior estabilidade, foram realizados estudos com o ácido anacárdico e os complexos de cobre (II) e de chumbo (II), preparados com diferentes técnicas a partir do extrato hexânico da casca da castanha do caju. Esses produtos foram testados, preliminarmente, em laboratório sobre caramujos adultos de B. glabrata.

\section{MATERIAL E MÉTODOS}

Preparação do extrato hexânico da casca da castanha do caju (EHCCC). As castanhas do caju foram coletadas em 1972 no município de Fortaleza, Ceará. Para separar a casca da castanha foi usada uma guilhotina adaptada no próprio laboratório usando uma tábua de madeira e uma faca de cozinha. As cascas foram trituradas na máquina manual, extraídas com nhexano no aparelho de Soxhlet e depois o solvente foi removido por destilação no rotavapor.

Preparação de complexos (Figura 3):

a. Complexo de chumbo (II), usando hidróxido de 
Mendes NM, Oliveira AB, Guimarães JE, Pereira JP, Katz N. Atividade moluscicida da mistura de ácidos 6 - $n$-alquil salicilicos (ácido anacáraico) e dos seus complexos com cobre (II) e chumbo (II). Revista da Sociedade Brasileira de Medicina Tropical 23: 217-224, out-dez, 1990.
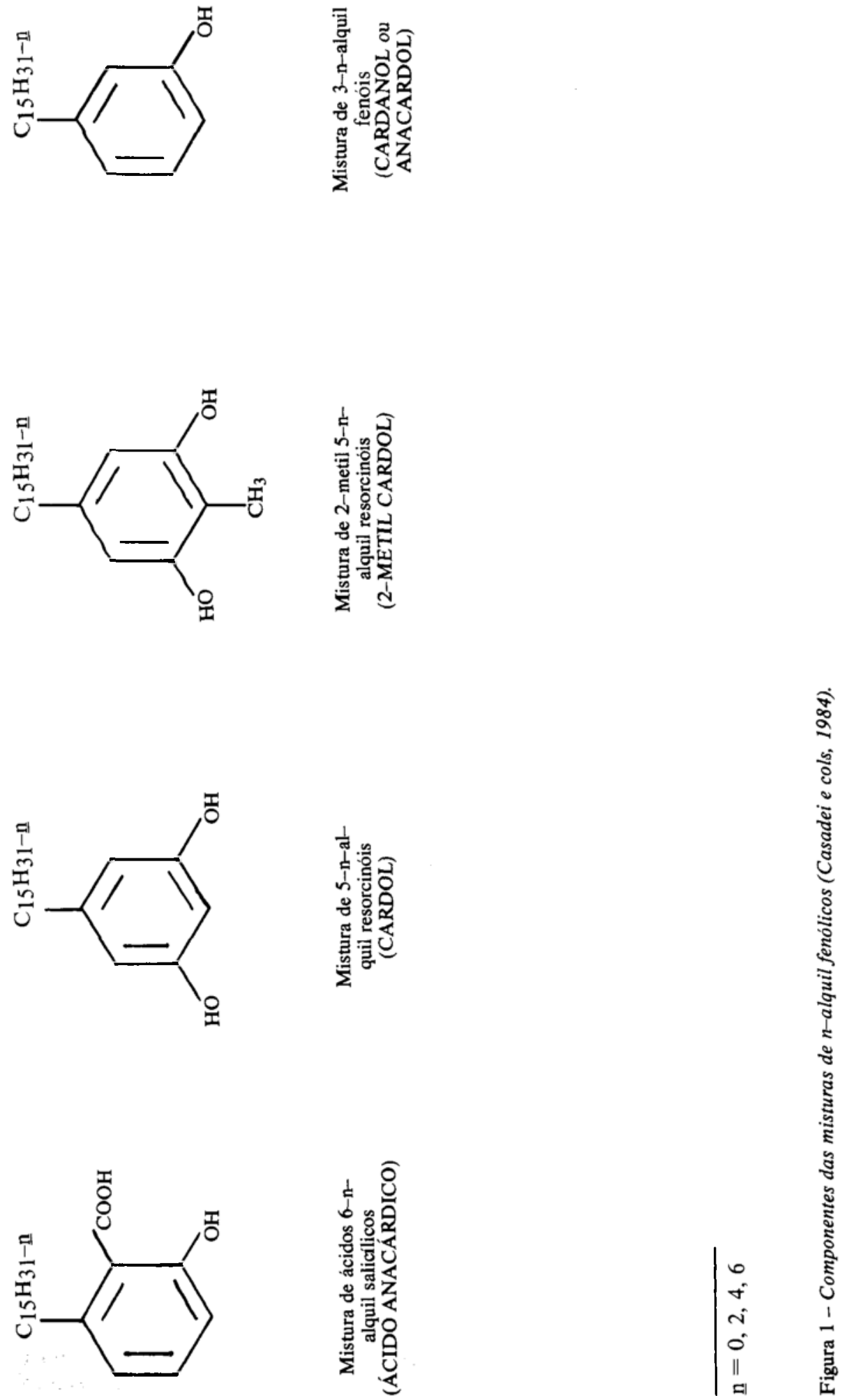
Mendes NM, Oliveira AB, Guimarães JE, Pereira JP, Katz N. Atividade moluscicida da mistura de ácidos 6 - $n$-alquil salicilicos (ácido anacárdico) e dos seus complexos com cobre (II) e chumbo (II). Revista da Sociedade Brasileira de Medicina Tropical 23: 217-224, out-dez, 1990.

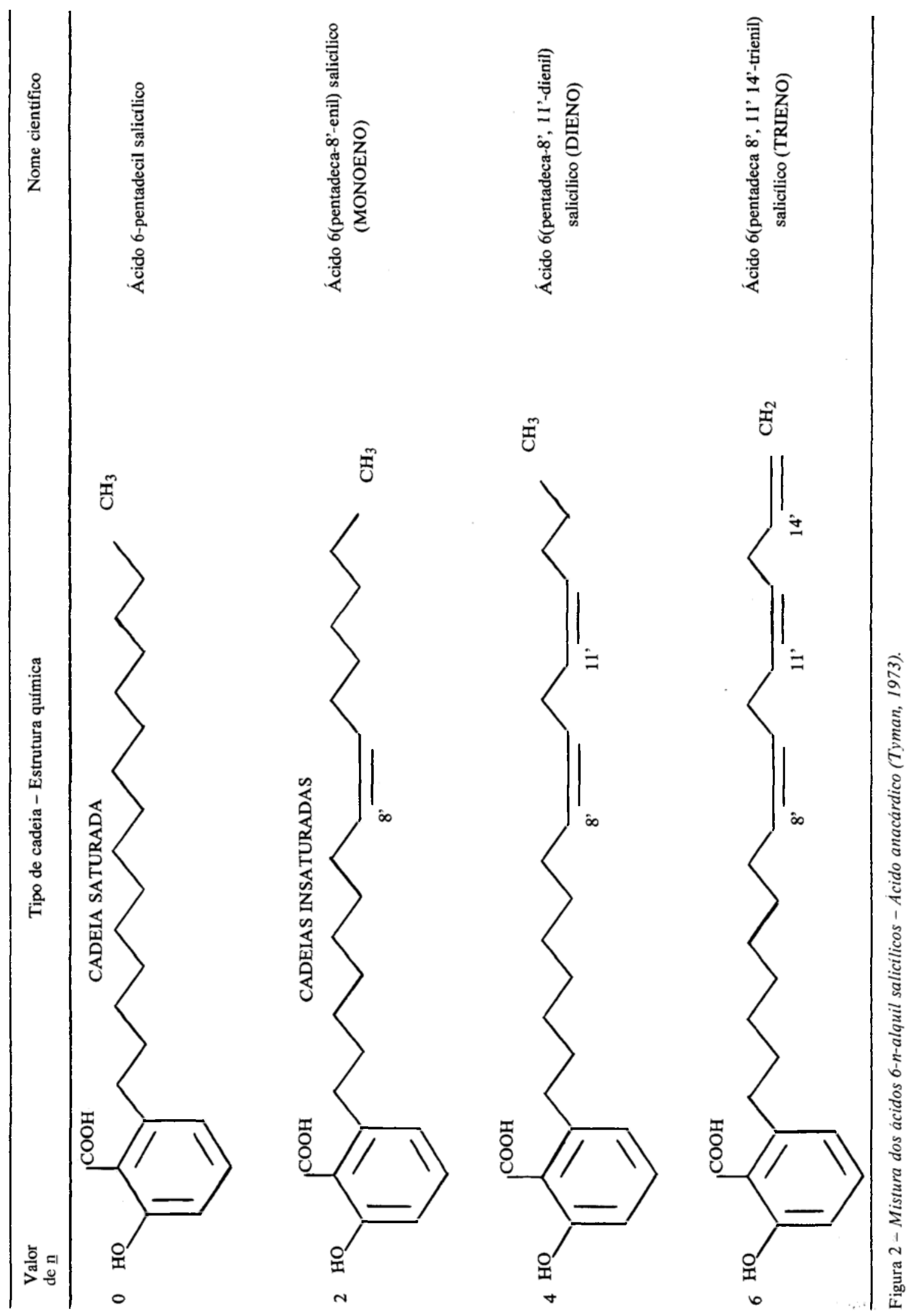


Mendes NM, Oliveira AB, Guimarães $J E$, Pereira JP, Katz $N$. Atividade moluscicida da mistura de ácidos 6-n-alquil salicilicos (ácido anacárdico) e dos seus complexos com cobre (II) e chumbo (II). Revista da Sociedade Brasileira de Medicina Tropical 23: $217-224$, out-dez, 1990.

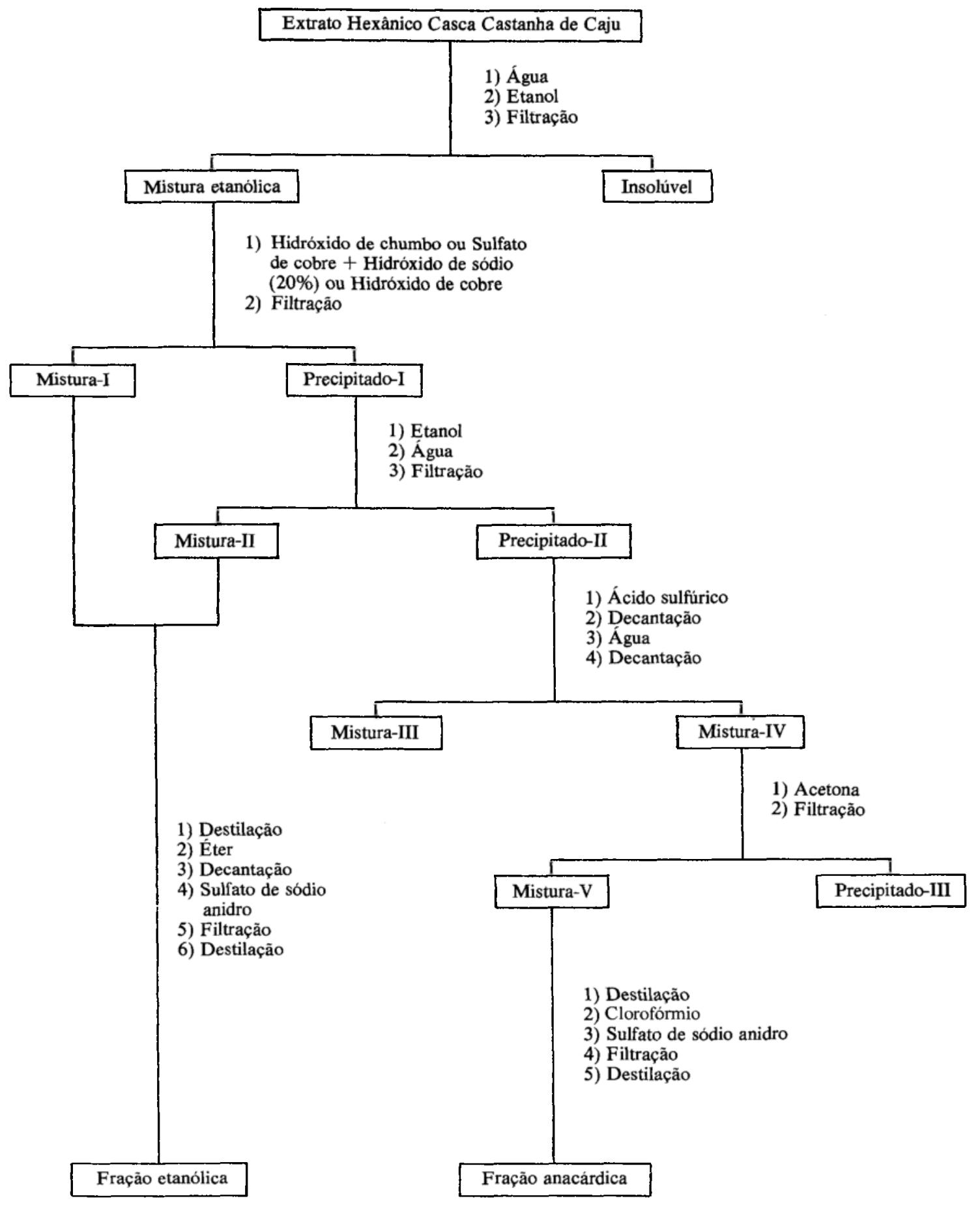

Precipitados I e II - complexo de chumbo (II) ou complexo de cobre (II)

Figura 3 - Obtençāo do ácido anacárdico e dos seus complexos. 
Mendes NM, Oliveira AB, Guimarães JE, Pereira JP, Katz $N$. Atividade moluscicida da mistura de ácidos 6 -n-alquil salicílicos (ácido anacárdico) e dos seus complexos com cobre (II) e chumbo (II). Revista da Sociedade Brasileira de Medicina Tropical 23: 217-224, out-dez, 1990.

chumbo(II) (Técnica de Eichbaum e cols) ${ }^{3}$. Foram lavados $10 \mathrm{~g}$ de EHCCC com água, dissolveu-se 0 decantado em $100 \mathrm{ml}$ de álcool etilico e filtrou-se a mistura etanólica, desprezando-se o material insolúvel. Essa mistura foi tratada, em banho de vapor, com hidróxido de chumbo (II), recentemente preparado, até que uma amostra da mistura não deu mais a reação violeta com cloreto férrico a $1 \%$. Filtrou-se a mistura no funil de Buchner e obteve-se o precipitado I de complexo (II). Este foi lavado com etanol e água e filtrou-se a mistura no funil de Buchner.

b. Complexo de cobre(II), usando sulfato de cobre(II) pentahidratado (Técnicas de Graddon e Munday, 1961; Mansur, 1981, adaptadas) ${ }^{49}$. Lavaram-se $2 \mathrm{~g}$ do EHCCC com água, dissolveu-se o decantado em $20 \mathrm{ml}$ de etanol e filtrou-se a solução, desprezandose $o$ insolúvel. Sob agitação constante, usando agitador magnético, adicionou-se à mistura etanólica, gota a gota, uma solução aquosa de quantidade equivalente de sulfato de cobre $(1 \mathrm{~mol}$ de ácido anacárdico para $1 \mathrm{~mol}$ de sulfato de cobre). Para manter o $\mathrm{pH}$ da mistura entre 12 e 13 adicionou-se gota a gota uma solução aquosa de hidróxido de sódio a $20 \%$. A agitação foi mantida por uma hora. Apos um repouso de meia hora, filtrou-se a mistura, obtendo-se o complexo de cobre (II). Lavou-se o precipitado I com etanol e água e filtrou-se a mistura.

c. Complexo de cobre (II), usando hidróxido de cobre (II) (Técnica de Misra e Kripal, 1981, adaptada) ${ }^{10}$. Após lavagem com água, dissolução em etanol e filtração de $2 \mathrm{~g}$ do EHCCC, adicionou-se à mistura etanólica, em banho de vapor, uma quantidade equivalente de hidróxido de cobre (II), recentemente preparado. Depois de aquecida durante uma hora, resfriada e filtrada, obteve-se o complexo de cobre (II). Lavou-se o precipitado I com álcool etílico e com água e filtrou-se a mistura.

Cada um dos precipitados II dos complexos obtidos foi colocado no dessecador até peso constante.

Obtenção de ácido anacárdico a partir do complexo de chumbo (II) ou complexo de cobre (II) (Figura 3) - Foi adicionado ao precipitado II de complexo de chumbo (II) ou de complexo de cobre(II) uma solução aquosa de quantidade equivalente de ácido sulfúrico, em banho de vapor, aquecendo-se durante quinze minutos. Após a decantaçāo, lavou-se com água por decantação e juntou-se acetona. $O$ precipitado III foi removido vácuo no funil de Buchner e destilou-se a propanona da mistura $V$ no rotavapor. Dissolveu-se o resíduo obtido em clorofórmio. Secouse com sulfato de sódio anidro, filtrou-se e destilou-se 0 clorofórmio no rotavapor.

Preparação da fração etanólica (Figura 3). Juntaram-se as misturas I e II obtidas na preparaçāo do complexo e destilou-se o etanol. Adicionou-se ao material éter etílico e a mistura etéria foi separada através do funil de decantaçāo. Tratou-se a mistura de éter com sulfato de sódio anidro, filtrou-se e destilou-se o solvente.
Testes como moluscicidas. Foram testadas preliminarmente em laboratório, as misturas do EHCCC, das fraçōes anacárdicas, do complexo de chumbo (II), dos complexos de cobre(II), das frações etanólicas, do sulfato de cobre, do ácido salicílico e da niclosamida em grupos de 20 caramujos adultos de $B$. glabrata. As conchas dos planorbideos mediam de 11-12 mm de diâmetro.

A mistura de cada produto na concentração de $10 \mathrm{ppm}$ foi preparada dissolvendo-se $10 \mathrm{mg}$ da substância em $0,3 \mathrm{ml}$ de metanol e completando-se o volume para $1000 \mathrm{ml}$ com água desclorada. As mirturas nas concentrações de 1, 2, 3, 4, 5 e 8 ppm foram obtidas através da diluição em água desclorada da mistura a $10 \mathrm{ppm}$. Utilizaram-se dois controles, um somente com água desclorada e o outro com uma solução aquosa com $0,3 \mathrm{ml}$ de álcool metílico.

O tempo de exposição dos moluscos em cada mistura foi de 24 horas. A temperatura e o $\mathrm{pH}$ das misturas foram medidos no início e no final de cada ensaio. A temperatura variou de 20 a $23^{\circ} \mathrm{C}$ e o $\mathrm{pH}$ foi de 6 e manteve-se constante durante o periodo do experimento ${ }^{14}$.

Testes químicos e fisicos. Do EHCCC, do complexo de cobre (II) e da fração anacárdica 2 (obtidos do tratamento do EHCCC com sulfato de cobre mais hidróxido de sódio) foram feitos espectros no infravermelho com o objetivo de comparar suas bandas de absorção e comprovar a formação do complexo metálico.

Analisaram-se os teores de chumbo e cobre das frações anacárdicas 1,2 e 3 preparadas, respectivamente, dos tratamentos com hidróxido de chumbo, sulfato de cobre e hidróxido de cobre através de espectrofotometria de absorção atômica.

Determinou-se o ponto de fusão do complexo de cobre (II) através do aparelho de Kolfler (Reichert Austria-Retec) com capacidade de até $310^{\circ} \mathrm{C}$.

Para detectar a presença de ácido anacárdico, as frações anacárdicas e etanólicas foram dissolvidas em clorofórmio. Em cada mistura clorofórmica foi adicionada solução aquosa de cloreto férrico a $1 \% 3$.

\section{RESULTADOS}

Os resultados dos 13 produtos ensaiados sobre caramujos adultos de $B$. glabrata nas concentrações de 1 a 10 ppm estão representados na Tabela 1 . As percentagens de mortalidade foram de: $100 \%$ para o EHCCC a partir da concentração de $5 \mathrm{ppm}$, para a fração anacárdica 2 a partir de 8 ppm e para as fraçōes etanólicas 2 e 3 na concentração de 10 ppm; $95 \%$ para a fração anacárdica 1 e $90 \%$ para o complexo de cobre (II) 2(4ppm). A fração anacárdica 3, o complexo de chumbo (II) 1 , o complexo de cobre (II) 3 , a fração etanólica 1 e o ácido salićlico não apresentaram atividades moluscicidas nas concentraçōes de 1 a 10 ppm. A niclosamida (Baylluscicie ${ }^{R}$ ) foi ativa a partir da concentração de $1 \mathrm{ppm}$ e o sulfato de cobre a partir de $2 \mathrm{ppm}$. Nos dois grupos controles não houve mortalidade. 
Mendes NM, Oliveira AB, Guimarães JE, Pereira JP, Katz $N$. Atividade moluscicida da mistura de ácidos 6-n-alquil salicílicos (ácido anacárdico) e dos seus complexos com cobre (II) e chumbo (II). Revista da Sociedade Brasileira de Medicina Tropical 23: 217-224, out-dez, 1990.

Tabela 1 - Atividade de produtos obtidos do Anacardium occidentale sobre caramujos adultos de Biomphalaria glabrata.

\begin{tabular}{|c|c|c|c|c|c|c|c|}
\hline \multirow[t]{2}{*}{$\begin{array}{l}\text { Produto } \\
\text { (Obtenção) }\end{array}$} & \multicolumn{7}{|c|}{$\begin{array}{l}\text { Percentagem de mortalidade - \% } \\
\text { Concentração em ppm }\end{array}$} \\
\hline & 1 & 2 & 3 & 4 & 5 & 8 & 10 \\
\hline $\begin{array}{l}\text { EHCCC } \\
\text { (Soxhlet) }\end{array}$ & 10 & 50 & 75 & 80 & 100 & 100 & 100 \\
\hline $\begin{array}{l}\text { Fração anacárdica } 1 \\
\text { (hidróxido de chumbo) }\end{array}$ & 10 & 20 & 60 & 95 & 100 & 100 & 100 \\
\hline $\begin{array}{l}\text { Fração anacárdica } 2 \\
\text { (sulfato de cobre) }\end{array}$ & 0 & 0 & 0 & 40 & 50 & 100 & 100 \\
\hline $\begin{array}{l}\text { Fração anacárdica } 3 \\
\text { (hidróxido de cobre) }\end{array}$ & 0 & 0 & 0 & 0 & 0 & 25 & 25 \\
\hline $\begin{array}{l}\text { Complexo de chumbo } 1 \\
\text { (hidróxido de chumbo) }\end{array}$ & 0 & 0 & 0 & 0 & 0 & 0 & 0 \\
\hline $\begin{array}{l}\text { Complexo de cobre } 2 \\
\text { (sulfato de cobre) }\end{array}$ & 10 & 10 & 50 & 90 & 100 & 100 & 100 \\
\hline $\begin{array}{l}\text { Complexo de cobre } 3 \\
\text { (hidróxido de cobre) }\end{array}$ & 0 & 0 & 0 & 0 & 0 & 0 & 0 \\
\hline $\begin{array}{l}\text { Fração etanólica } 1 \\
\text { (hidróxido de chumbo) }\end{array}$ & 0 & 0 & 0 & 0 & 10 & 10 & 20 \\
\hline $\begin{array}{l}\text { Fração etanólica } 2 \\
\text { (sulfato de cobre) }\end{array}$ & 0 & 0 & 0 & 20 & 50 & 50 & 100 \\
\hline $\begin{array}{l}\text { Fração etanólica } 3 \\
\text { (hidróxido de cobre) }\end{array}$ & 0 & 0 & 0 & 20 & 50 & 50 & 100 \\
\hline $\begin{array}{l}\text { Sulfato de cobre } \\
\text { (Usina Colombina) }\end{array}$ & 10 & 100 & 100 & 100 & 100 & 100 & 100 \\
\hline $\begin{array}{l}\text { Ácido salicílico } \\
\text { (Backer) }\end{array}$ & 0 & 0 & 0 & 0 & 0 & 0 & 0 \\
\hline $\begin{array}{l}\text { Niclosamina } \\
\text { (Bayer) }\end{array}$ & 100 & 100 & 100 & 100 & 100 & 100 & 100 \\
\hline
\end{tabular}

$\overline{\mathrm{EHCCC}}=$ Extrato hexânico da casca da castanha de caju.

Os espectros no infravermelho do complexo de cobre (II) 2 em relação ao EHCCC e à fração anacárdica 2 ocorreram alterações das bandas de absorção características dos grupos hidróxila fenólico e carbonila carboxílica evidenciando a formação do complexo.

O teor de chumbo da fração anacárdica 1 foi de 429 ppm e os teores de cobre das frações anacárdicas 2 e 3, respectivamente, foram de 2,5 e 2,8 ppm.

$O$ ponto de fusão do complexo de cobre(II) 2 foi acima de $310^{\circ} \mathrm{C}$.

Nas frações anacárdicas 1, 2 e 3, nas etanólicas 2 e 3 foram constatadas a presença de ácido anacárdico quando testadas com cloreto férrico. $\mathrm{Na}$ fração etanólica 1 não foi detectado o ácido anacárdico ${ }^{3}$.

\section{DISCUSSÃO}

As CL90 do EHCCC testados sobre $B$. glabrata foram de 2,8 ppm para os caramujos adultos,
0,75 ppm para os recém-eclodidos e 33,00 ppm para as desovas. Esse extrato apresentou $100 \%$ de mortalidade para cercárias de Schistosoma mansoni e Lebistes reticulatus (piaba) nas concentrações de 10 ppm, mas não demonstrou toxidez para roedores ( $M u s$ musculus) na concentração de 100 ppm. A atividade do extrato aquoso da casca da castanha de caju em criadouro de $B$. glabrata foi na concentração de 20 ppm 12 .

Os componentes do caju foram separados por cromatografia líquida de alta eficiencia 7 15. As CL50 e CL90 para $B$. glabrata dos constituintes do ácido anacárdico de cadeias insaturadas foram, respectivamente, 1,4 e 1,9 ppm para o monoeno, 0,9 e 1,4 ppm para o dieno e 0,4 e 0,7 ppm para o trieno. $O$ ácido salicílico, o ácido anacárdico de cadeia saturada e o cardanol apresentaram as concentraçoes letais maiores que $5 \mathrm{ppm}^{15}$. As CL50 para $B$. glabrata foram 1,0 
Mendes NM, Oliveira AB, Guimarāes JE, Pereira JP, Katz $N$. Atividade moluscicida da mistura de ácidos 6 -n-alquil salicilicos (ácido anacárdico) e dos seus complexos com cobre (II) e chumbo (II). Revista da Sociedade Brasileira de Medicina Tropical 23: $217-224$, out-dez, 1990.

ppm para o monoeno, $0,6 \mathrm{ppm}$ para o dieno e $0,3 \mathrm{ppm}$ para o trieno. Para os constituintes do cardol, do 2metilcardol e do cardanol foram acima de $6 \mathrm{ppm}^{7}$.

As experiências de laboratório com a mistura aquosa de resíduo industrial do caju demonstrou $100 \%$ de mortalidade para Bulinus globosus em concentrações iguais ou superiores a $500 \mathrm{ppm}$. Esse resíduo quando colocado uma só vez em água de baixa ou nula correnteza em valas de irrigação do Rio Incomati (Maputo - Moçambique) produziu uma diminuição da densidade do molusco da ordem de 86,5 a $97,8 \%$ na concentração de $1000 \mathrm{ppm}$, ao fim de cinco meses 11 .

Casadei e cols, em 1984, extraíram ácido anacárdico, cardol e cardanol do extrato hexânico do resíduo industrial através de cromatografia 1 . $O$ ácido anacárdico apresentou $100 \%$ de mortalidade para $B$ globosus na concetração de $100 \mathrm{ppm}$ e o cardol e o cardanol não demonstraram nenhuma atividade.

No presente trabalho, observou-se que a atividade do EHCCC sobre caramujos adultos de $B$. glabrata foi inferior aos relatados por Pereira e Souza 12 .

As cascas das castanhas de caju para a obtenção do EHCCC deste trabalho e de Pereira e Souza12, em 1974, procederam do mesmo local (Fortaleza, CE) e foram coletados na mesma época do ano (1972). Portanto, a variação da ação moluscicida quando comparados os dois extratos, ocorreu provavelmente em conseqüência da polimerização da cadeia lateral do ácido anacárdico ${ }^{6}$ ou de sua descarboxilação 11 .

A fração anacárdica 1 e o complexo de cobre (II) 2 foram mais ativos que o EHCCC e que as frações anacárdicas 2 e 3 (Tabela 1). Por outro lado, a fração anacárdica 1 obtida do tratamento do EHCCC com hidróxido de chumbo (II) mostrou um teor de chumbo acima das normas recomendadas pelos $\mathrm{Pa}$ drões de Saúde Pública dos Estados Unidos (não devem exceder de $0,1 \mathrm{ppm}$ ) não se justificando, portanto, a sua utilização. As frações anacárdicas 2 (sulfato de cobre) e 3 (hidróxido de cobre) apresentaram os teores de cobre de acordo com as normas $(3 \mathrm{ppm})^{5}$.

Sumarizando, o processo de estabilização do ácido anacárdico pode ser obtido pela complexação com o cobre (II) (sulfato de cobre mais hidróxido de sódio), o qual demonstrou possuir também acentuada atividade moluscicida.

\section{SUMMARY}

The molluscicide activity of hexanic extract from Anacardium occidentale $L$. (cashew) nut shell, of copper(II) complex, of lead (II) complex and anacardic acid has been compared in the laboratory in an attempt to obtain better stability than anacardic acid. This was obtained from the hexanic extract of the cashew nut shell by precipitation with lead (II) hydroxide or cupric sulfate plus sodium hydroxide or (II) cupric hydroxide followed by treatment of lead (II) complex with a diluted solution of sulfuric acid. Ten products of the mixture obtained were tested on adults snails of
Biomphalaria glabrata at 1 to $10 \mathrm{ppm}$. The most active products were copper (II) complex, obtained by cupric sulfate plus sodium hydroxide, and anacardic acid (sodium hydroxide) which presented activits at 4 ppm. The anacardic acid's lead content was above the limits accepted by the United States standards.

Key-words: Biomphalaria glabrata. Anacardic acid. Complexes. Molluscicide.

\section{AGRADECIMENTOS}

Ao Prof. Emílio Osório Neto, do Centro Tecnológico de Minas Gerais (CETEC) e do Departamento de Química da UFMG, pelas análises dos teores de cobre e de chumbo; à Dra. Cecilia Pereira de Souza, do Laboratório de Malacologia de Centro de Pesquisas "René Rachou" (CPqRR), pelo fornecimento dos caramujos; ao Sr. Moacyr Rodrigues da Silva, do Laboratório de Química de Produtos Naturais do CPqRR, pela separação e trituração das cascas das castanhas de caju e a Bernadete Patrícia Santos, secretária do Laboratório de Esquistossomose do $\mathrm{CPqRR}$, pelo serviço datilográfico.

\section{REFERÊNCIAS BIBLIOGRÁFICAS}

1. Casadei E, Bruheim S, Latis T. Princípios activos da casca da castanha de caju com açāo moluscocida: possível emprego no programa de luta contra a esquistossomose. Revista Médica de Moçambique 2: 35-39, 1984.

2. Corrêa MP. Dicionário de plantas úteis e das exóticas cultivadas. Empresa Gráfica Gutenberg LTDA, Rio de Janeiro, RJ, 1. ediçào, 1: 400-402, 1984.

3. Eichbaum F, Hauptmann H, Rostschild H. Preparaçāo e ação biológica do ácido anacárdico e de alguns derivados. Anais da Associação Química do Brasil 4: 83-94, 1945.

4. Graddon DP, Munday L. Some properties of copper(II) - amino acid chelates. A study of solubilities. Visible region and infra-red spectra in relation to crystal structure. Journal Inorganic Nuclear Chemistry 23: 231-244, 1961.

5. Handernbergh WA. Abastecimento e purificaçāo da água. Serviço de Saúde Pública, Rio de Janeiro, RJ, 2! edição, 271, 1958.

6. Izzo PT, Dawson CR. Cashew nut shell liquid VI. The olefinic nature of anacardic acid. Journal of Organic Chemistry 4: 1039-1047, 1949.

7. Kubo I, Komatsu S, Ochi M. Molluscicides from the cashew Anacardium occidentale and their large-scale isolation. Journal of Agricultural Food Chemistry 34: 970-973, 1986.

8. Lloyd HA, Denny C, Krishna G. A simples liquid chromatographic method for analysis and isolation of the unsaturated components of anacardic acid. Journal of Liquid Chromatography 3: 1497-1504, 1980.

9. Mansur NHS. Comportamento radiolítico estabilidade térmica de N, N -BIS (2-aminoetil) malondiamida de cobre (II) e niquel (II). Tese de doutorado, Universidade Federal de Minas Gerais, Belo Horizonte, 1981. 
Mendes NM, Oliveira AB, Guimarães JE, Pereira JP, Katz N. Atividade moluscicida da mistura de ácidos 6-n-alquil salicilicos (ácido anacárdico) e dos seus complexos com cobre (II) e chumbo (II). Revista da Sociedade Brasileira de Medicina Tropical 23: 217-224, out-dez, 1990.

10. Misra BN, Kripal R. Infrared band assignments of copper amino acid complexes. Acta Physica Polonica A59: $425-429,1981$.

11. Monteiro OAC, Freire MTG, Barreira SRT. Líquido da casca da castanha de caju. Novas oportunidades industriais. Revista Química Industrial 232: 8-10, 1985.

12. Pereira JP, Souza CP. Ensaios preliminares com "Anacardium occidentale" como moluscicida. Ciência e Cultura, São Paulo 26: 1054-1057, 1974.

13. Soria GP, Lourenço MI, Rey L. Controle de populações de Bulinus globosus transmissores da esquistossomose em Moçambique, com moluscocida vegetal. Revista Médica de Mocambique 2: 75-79, 1982.

14. Souza CP, Azevedo MLL, Lopes JLC, Sarti SJ, Santos
Filho D, Lopes JNC, Vichnewski W, Nasi AMTT, Leitão Filho, HF. Quimioprofilaxia da esquistossomose: Atividade moluscicida de produtos naturais Ensaios com caramujos adultos e desovas. Anais da Academia Brasileira de Ciências 56: 333-338, 1984.

15. Sullivan JT, Richards CS, Lloyd HA, Krishna G. Anacardic acid: molluscicide in cashew nut shell liquid. Journal of Plants Medica 44: 175-177, 1982.

16. Tyman JHP. Long-chain phenols. Part III. Identification of the componentes of a novel phenolic fraction in Anacardium occidentale (cashew nut-shell liquid) and synthesis of the saturated member. Journal of the Chemistry Society Perkin I: 1639-1647, 1973. 